\title{
Self-stigma and treatment effectiveness in patients with anxiety disorders - a mediation analysis
}

This article was published in the following Dove Press journal:

Neuropsychiatric Disease and Treatment

\author{
Marie Ociskova' \\ Jan Prasko' \\ Kristyna Vrbova' \\ Petra Kasalova' \\ Michaela Holubova' \\ Ales Grambal' \\ Klara Machu² \\ 'Department of Psychiatry, Faculty \\ of Medicine and Dentistry, Palacky \\ University, University Hospital, \\ Olomouc, ${ }^{2}$ Department of Psychology, \\ Faculty of Arts, University of Ostrava, \\ Ostrava, The Czech Republic
}

Goal: The goal of this study was to explore the impact of self-stigma on the treatment outcomes in patients with anxiety disorders and to find possible mediators of this relationship.

Method: Two hundred and nine patients with anxiety disorders, who were hospitalized in a psychotherapeutic department, attended the study. The average age was 39.2 \pm 12.4 years; two-thirds were women. Most of the patients used a long-term medication. The participants underwent either cognitive behavioral therapy (CBT) or short psychodynamic therapy. The selection to the psychotherapy was not randomized. All individuals completed several scales - Beck Depression Inventory, the second edition (BDI-II), Beck Anxiety Inventory (BAI), Dissociative Experience Scale (DES), Sheehan Disability Scale (SDS), subjective Clinical Global Impression (subjCGI), and The Internalized Stigma of Mental Illness Scale (ISMI). A senior psychiatrist filled out the objective CGI (objCGI).

Results: The patients significantly improved in the severity of anxiety (BAI), depression (BDI-II), and overall severity of the mental disorder (objCGI). The self-stigma predicted a lower change of the objCGI, but not a change of the anxiety and depressive symptoms severity. Anxiety, depressive symptoms, dissociation, and disability were assessed as possible mediators of the relationship between the self-stigma and the treatment change. None of them were significant.

Conclusion: Self-stigma lowers the effectiveness of the combined treatment of anxiety disorders. Future research should explore other possible mediators influencing this relationship.

Keywords: self-stigma, anxiety disorders, treatment effectiveness, medication

\section{Introduction}

During the last two decades, researchers have increasingly focused on a specific type of patients' understanding of their mental issues - one which stems from the mental illness stereotypes and prejudices. ${ }^{1}$ It has been found that some patients, who are aware of the prejudices, agree with them, and subsequently apply them in their case. This type of interpretation of one's mental struggles is known as self-stigma. ${ }^{1}$

Through negative lenses of stigma, an individual attributes his mental struggles to internal, unchangeable, and global causes (which makes self-stigma related to the depressive attributional style described by Seligman et $\mathrm{al}^{2}$ ). In accordance with widespread prejudices, the patient may think that he is somehow inferior, weak, unwanted, or unreliable because of his mental issues. ${ }^{3}$ As these interpretations tend to be rigidly held, and as they are unrealistically negative and unbalanced ("I am weak, inferior, different, ..."), the self-stigma induces stress. ${ }^{4}$

When the individual stigmatizes himself, his self-esteem declines. ${ }^{5,6}$ Thinking that one is weak or inferior, the patient loses trust in oneself. A loss of a sense of mastery and hopelessness follow. ${ }^{6-8}$ As a result of the changes in self-concept, symptoms of anxiety and depression occur or are exacerbated. ${ }^{5,9}$
Correspondence: Marie Ociskova Department of Psychiatry, University Hospital Olomouc, IP Pavlova 6, 77520 Olomouc, The Czech Republic

Tel +420588443513

Email marie.ociskova@upol.cz 
Self-stigma has also been related to dissociation. Patients with high rates of self-stigma express high dissociation levels. ${ }^{9,10}$ Both factors are associated with worse treatment outcomes. ${ }^{7,11}$ It is possible that they are the result of aversive childhood experiences. ${ }^{12}$ Self-stigma is related to negative core beliefs that are predominantly formed in childhood and relate to early aversive experiences. ${ }^{12}$ Excessive use of dissociation also develops in childhood, when the child is exposed to traumatic experiences that they cannot handle other than by the splitting of integrative mental functions, such as memory, emotions, cognition, and physical perceptions. ${ }^{10}$

Some changes, which result from self-stigmatization, may also be noticed in the patients' social behavior. ${ }^{6}$ A person who stigmatizes himself is often afraid that others could do the same to him. Because of this fear, the individual may try to conceal their mental issues or isolate themselves from society and loved ones. ${ }^{13}$ Self-stigma worsens social functioning. ${ }^{8}$

The changes in self-concept and related demoralization are also reflected in the treatment. ${ }^{14,20}$ Stigma has been connected with worse adherence in the pharmacotherapy of mental disorders, ${ }^{15,16}$ and with worse attendance on psychosocial rehabilitation programs. ${ }^{17}$ The self-stigmatizing patients tend to discontinue medication of their own will, or do not follow the necessary treatment regime. ${ }^{15}$ As for the anxiety disorders, self-stigma leads to lower effectiveness of the pharmacotherapy ${ }^{16}$ and the combined treatment of psychotherapy and pharmacotherapy. ${ }^{9}$ Despite the intensive treatment, patients with self-stigmatizing tendencies often remain significantly anxious and improve less than those who do not stigmatize themselves..$^{9,11}$

Anxiety disorders are among the most prevalent mental conditions, ${ }^{18}$ with a considerable degree of disability. ${ }^{19}$ At the same time, only $\sim 60 \%$ of anxiety disorder patients react significantly to the standardized treatments. ${ }^{20}$ Ranging from generalized anxiety disorder ${ }^{21}$ and social phobia ${ }^{22}$ to panic disorder and agoraphobia, ${ }^{23}$ all anxiety disorders show a similar pattern of commonly insufficient treatment results. ${ }^{24}$

Several maintenance factors for anxiety disorders have been found. Some present psychosocial variables which prevent the patients from reaching remission. Rigidly held cognitive errors, maladaptive schemas, and avoidant behavior, ${ }^{25}$ early life experiences, ${ }^{26}$ dissociations, ${ }^{10}$ and self-stigma ${ }^{16}$ negatively influence the treatment response. Biological factors, such as genetics ${ }^{27}$ and temperament, ${ }^{26}$ also play a role. While some factors may be addressed during the treatment more readily than others (eg, cognitive errors versus maladaptive schemas), the current state of treatment effectiveness leaves much to be desired. It is vital to explore the impact of the maintenance factors on the treatment outcomes and how they work. Better exploration of this field may lead to improvements in the standardized treatments to make them more efficacious.

Self-stigma has only recently been shown to influence the treatment results in patients with anxiety disorders. ${ }^{9,16}$ Although considerable attention has been paid to self-stigma in people with psychosis, ${ }^{8,17,28}$ it is also a significant issue for many individuals with anxiety disorders. ${ }^{9,29}$ Still, it is not known in which ways self-stigma maintains the psychopathology.

According to several authors, ${ }^{5,30}$ self-stigma increases anxiety. Thus, it may worsen the treatment outcomes through the maintenance of anxiety. Link et $\mathrm{al}^{31}$ also found that self-stigma predicted the severity of depressive symptoms. Hopelessness, helplessness, and related depressive symptoms have been connected to self-stigma ${ }^{6}$ and, as such, can lead to unfavorable treatment results too. Anxiety and depression are also associated with dissociation. ${ }^{9}$ By splitting the consciousness, the process of therapy is blunted. Moreover, since self-stigma negatively influences functioning in life, ${ }^{6}$ it is possible that this disability may function as another mediator of the relationship between internalized stigma and treatment effectiveness.

Since this topic has not yet been sufficiently explored, and since self-stigma seems to play a significant role in the treatment of anxiety disorders, there were two goals in this study. The first goal was to confirm or disconfirm that self-stigma leads to worse outcomes for combined pharmacological and psychotherapeutic treatment of anxiety disorders. The second goal was to find if anxiety, depressive symptoms, dissociation, or disability are mediators of this relationship.

The hypotheses were as follows:

(1) The higher initial level of self-stigma (The Internalized Stigma of Mental Illness Scale [ISMI]) predicts the lower relative change of anxiety symptoms during the treatment (Beck Anxiety Inventory [BAI]).

(2) The higher initial level of self-stigma (ISMI) predicts the lower relative change of depressive symptoms during the treatment (Beck Depression Inventory, the second edition [BDI-II]).

(3) The higher initial level of self-stigma (ISMI) predicts the lower relative change of the overall mental state during the treatment, assessed by a clinician (objective Clinical Global Impression [objCGI]).

A main indicator of the treatment effect was the relative change of the overall psychopathology. The reasons for this choice were the general character of the evaluation (the assessment of the whole mental state instead of symptom 
clusters, such as anxiety or depressivity) and its objective nature (BAI, BDI-II, and Dissociative Experience Scale [DES] are self-evaluative; see the Methods section). As such, the relative change of the psychopathology assessed by a psychiatrist entered a fourth hypothesis dealing with the mediation:

(4) The relationship between the higher initial self-stigma (ISMI) and lower relative change of the overall mental state (objCGI) is mediated by:

(a) The anxiety symptoms measured at the beginning of the treatment (BAI).

(b) The depressive symptoms measured at the beginning of the treatment (BDI-II).

(c) The level of dissociation measured at the beginning of the treatment (DES).

(d) Functioning in social life, assessed at the beginning of the treatment (Sheehan Disability Scale [SDS]).

(e) Functioning in family life, assessed at the beginning of the treatment (SDS).

(f) Functioning in occupation, assessed at the beginning of the treatment (SDS).

\section{Sample and method Sample}

Patients who had been hospitalized in a psychotherapeutic department between November 2012 and June 2016 were asked to participate in the study. Two hundred and nine individuals with anxiety disorders agreed, signed an informed consent form, and filled in several scales. The inclusion criteria were:

(1) Aged 18-70 years.

(2) A diagnosis of an anxiety disorder according to ICD$10^{32}$ - a social phobia, a panic disorder with/without agoraphobia, a generalized anxiety disorder, or a mixed anxiety-depressive disorder.

The exclusion criteria were:

(1) A diagnosis of an organic mental illness, intellectual disability, a psychosis, or an antisocial personality disorder.

(2) Severe suicidal tendencies.

Psychiatric diagnostics was realized by an outpatient psychiatrist, a psychiatrist of the department, and a senior psychiatrist.

\section{Measurements}

The inpatients who decided to contribute to the investigation signed an informed consent form and completed several questionnaires. All were assessed by two psychiatrists for diagnostic evaluation and by a psychologist to confirm the diagnosis with a standard diagnostic interview Mini International Neuropsychiatric Interview (MINI). ${ }^{33}$ These assessment tools were completed at the start and the end of hospitalization:

- $\mathrm{MINI}^{33}$ is a standard diagnostic interview covering diagnostic criteria for common psychiatric disorders according to DSM-IV and ICD-10. Sensitivity is higher than 0.70 for all reviewed disorders except for dysthymia, obsessive compulsive disorder, and current drug dependence. Specificity is higher than 0.85 for all diagnoses. ${ }^{33}$

- $\mathrm{CGI}^{34}$ is used for the global evaluation of the severity of the disorder. In this study, the objective (evaluated by a psychiatrist) and subjective (assessed by the patient) evaluation of CGI severity were used. The level of agreement between raters reaches an intra-class correlation coefficient of $0.90 .^{35}$

- $\mathrm{BAI}^{36}$ contains 21 items - anxiety symptoms - on a fourpoint Likert scale. The participant indicates symptoms and their severity during the last week. The scale has excellent internal consistency (mean $\alpha=0.91$ ). ${ }^{37}$ The validation of the Czech translation was done with excellent Cronbach alfa $=0.92 .{ }^{38}$

- BDI-II ${ }^{39}$ includes 21 items from which patients choose depressive symptoms and rate their severity. Patients assess their state during the previous week. Internal consistency of the scale is higher in the psychiatric population $(\alpha=0.86)$ than in the general population $(\alpha=0.81) .{ }^{40} \mathrm{Czech}$ standardization was performed by Ociskova et $\mathrm{al}^{41}$ with Cronbach's alfa $=0.90$.

- $\mathrm{ISMI}^{42}$ assesses the level of self-stigma in adults with diagnosed psychiatric disorders. It consists of 29 items distributed into five subscales - alienation, stereotype endorsement, discrimination experience, social withdrawal, and stigma resistance. Patients mark one number from a four-point Likert scale according to the level of consent with each statement. ${ }^{42}$ Cronbach's alpha of the method is excellent $(\alpha=0.90)$. The Czech version of the scale has an equivalent internal consistency $(\alpha=0.91){ }^{43}$ The following methods were completed only at the start of the treatment:

- $\mathrm{DES}^{44}$ defines 28 dissociative experiences. The patient marks a spot on a $10 \mathrm{~cm}$ line according to the frequency of feeling the symptoms. The pathological type of dissociation can be identified by a subgroup of eight items of the DES, the DES-Taxon (DES-T). ${ }^{44}$ This subscale involves eight out of the 28 DES items (items 3, 5, 7, 8, 12, 13, 22, and 27). ${ }^{45}$ The original Cronbach's alpha is $0.93 .{ }^{44}$ The Czech version of the scale has similar validity, test-retest reliability, and factor structure to the original one. ${ }^{46}$ 
- $\operatorname{SDS}^{47,48}$ is a patient-assessed, analog measure of functional disability in work, social, and family life. A patient rates the extent to which these areas of life are impaired on a 10 point scale. ${ }^{49}$ Arbuckle et al $^{50}$ stated a Cronbach's alpha of 0.89 .

- The demographic questionnaire checked the basic information about the patients, such as gender, age, age of disease onset, education, employment status, pension status, duration of attendance in the outpatient clinic, number of hospitalizations, time since the last hospitalization, current medication, number of visited psychiatrists, and discontinuation of drugs in the past (recommended by a psychiatrist or arbitrarily).

The study primary outcome criteria were defined as:

- Relative change during the therapy in objCGI and BAI (the difference between rating at the beginning and rating at the end of the therapy divided by the beginning score).

\section{Methods of treatment}

\section{Psychopharmacotherapy}

Patients were treated with standard doses of psychopharmacs. Medication was changed minimally. There was no significant difference between the antidepressant dosage at the beginning and at the end of the hospitalization (the starting dosage in 180 patients was $42.7 \pm 27.0 \mathrm{mg}$ of paroxetine equivalent; the dosage at the end in 187 patients was $40.4 \pm 24.3 \mathrm{mg}$; paired $t$-test: $t=1.416, d f=177$; not significant [ns]). Similarly, the mean dosage of the anxiolytics did not change (the starting dosage in 70 patients was $5.2 \pm 6.2 \mathrm{mg}$ of diazepam equivalent; the ending dosage in 37 patients was $6.9 \pm 7.7 \mathrm{mg}$; paired $t$-test: $t=0.712 ; d f=32 ; \mathrm{ns})$. Also, the mean dosage of antipsychotics did not significantly change during the treatment (the starting dosage in 45 patients was $1.1 \pm 1.1 \mathrm{mg}$ of risperidone equivalent; the ending dosage in 59 patients was $1.4 \pm 2.1 \mathrm{mg}$; paired $t$-test: $t=-0.679 ; d f=39$; ns). Mood stabilizers were used in eight patients at the beginning and 12 patients at the end of the hospitalization.

\section{Psychotherapy}

The psychotherapy was provided in two different forms: cognitive behavioral therapy (CBT) or brief psychodynamic therapy, both in a 6-week treatment program. The patients were not randomized to the type of psychotherapy. Patients were present for 30 group sessions (CBT or short psychodynamic therapy) and five individual sessions. The CBT program included therapeutic activities such as psychoeducation, case conceptualization, work with automatic thoughts and schemas, exposures, and problem-solving. ${ }^{10}$ Short psychodynamic therapy concentrated on relational problems in a patient's life and group interactions, which were both related to a person's development. The program for both groups was supplemented with assertive training, mental imagery, relaxation, sport, and ergotherapy.

\section{Statistics}

Statistics were calculated by using statistical software PRISM (GraphPad PRISM version 5.0), SPSS 24.0, and AMOS. The applied statistical methods were descriptive statistics for the demographic data, mean scores, and normality tests. Differences between scores were calculated by parametric or nonparametric paired or unpaired $t$-tests or Kruskal-Wallis tests. Correlations were used to analyze the relationships between the treatment outcome and other factors. Effect sizes were interpreted by Cohen. ${ }^{51}$ A mediation analysis was performed by using the maximum likelihood method with standardized estimates. Differences were considered to be significant when $P$-values were less than 0.05 .

\section{Ethics}

The research was performed in agreement with the latest version of the Helsinki Declaration and the Guideline for Good Clinical Practice. ${ }^{52}$ The ethical committee of the University Hospital in Olomouc, the Czech Republic, approved the study. Written informed consent was received from all participants after the procedures had been fully explained.

\section{Results \\ Descriptive and clinical characteristics of the sample}

Questionnaires were completed by 209 patients (72.1\%) from 290 hospitalized at the time of completing the study, and who met the entry criteria. The data of the 209 patients were statistically analyzed. Data of $81(27.9 \%)$ patients were not used, as 22 patients prematurely dropped out from the treatment due to various reasons, the diagnosis was changed in 48 participants, and 11 individuals did not fulfill questionnaires at the end of the study.

The patients' average age was $39.2 \pm 12.4$ years, and the duration of the disorder was 9.7 \pm 9.7 years (Table 1). There were slightly more women $(66 \%)$ than men. The education received was relatively regularly distributed: $10.5 \%$ of the patients had basic education, 29.2\% underwent vocational training, $44.5 \%$ had secondary education, and $15.8 \%$ reached university level. When we looked at the employment status, the results showed that $38.3 \%$ of the patients were unemployed 
Table I Descriptive and clinical characteristics of the sample and changes during the treatment

\begin{tabular}{|c|c|}
\hline Factor & Number or mean \\
\hline Number of the patients & 209 \\
\hline Age, years & $39.2 \pm 12.4$ \\
\hline Gender: male/female & $71(34 \%) / 138$ (66\%) \\
\hline Education: primary/vocational training/ & $22(10.5 \%) / 6 \mid(29.2 \%) /$ \\
\hline secondary/tertiary & $93(44.5 \%) / 33(15.8 \%)$ \\
\hline Employed: Yes/No & $129(61.7 \%) / 80(38.3 \%)$ \\
\hline Pension: Yes/No & $29(13.9 \%) / 180(86.1 \%)$ \\
\hline Marital status: single/married/divorced/ & $88(42.1 \%) / 76(36.4 \%) /$ \\
\hline widowed & $39(18.7 \%) / 6(2.9 \%)$ \\
\hline Partner: Yes/No & $122(58.4 \%) / 87$ (4I.6\%) \\
\hline \multirow[t]{3}{*}{ Disorder: AP/SP/PD/GAD/MADD } & $13(6.2 \%) / 43(20.6 \%) /$ \\
\hline & $64(30.6 \%) / 55(26.3 \%) /$ \\
\hline & $34(11.7 \%)$ \\
\hline Comorbid personality disorder: Yes/No & $33(\mathrm{I} 5.8 \%) / \mathrm{I} 76(84.2 \%)$ \\
\hline Comorbid depression: Yes/No & $16(7.7 \%) / 193(92.3 \%)$ \\
\hline Comorbid anxiety disorder: Yes/No & $52(24.9 \%) / 157$ (75.1\%) \\
\hline Onset of the disorder in years & $29.5 \pm 13.8$ \\
\hline Number of psychiatric hospitalizations & $1.8 \pm 2.0$ \\
\hline Length of the treatment in years & $9.7 \pm 9.7$ \\
\hline Positive familial anamnesis: Yes/No & II 5 (55.0\%)/94 (45.0\%) \\
\hline Psychotherapy: CBT/short & $89(42.6 \%) / 120(57.4 \%)$ \\
\hline \multicolumn{2}{|l|}{ psychodynamic therapy } \\
\hline objCGI: At the start of the treatment & $4.4 \pm 1.0$ \\
\hline At the end of the treatment & $2.7 \pm 1.1$ \\
\hline Paired $t$-test & $t=21.767 ; d f=204 ; P<0.001$ \\
\hline subjCGI: At the start of the treatment & $4.4 \pm 1.3$ \\
\hline At the end of the treatment & $3.3 \pm 1.3$ \\
\hline Paired $t$-test & $t=9.089 ; d f=|85 ; P<0.00|$ \\
\hline BAl: At the start of the treatment & $25.0 \pm 11.7$ \\
\hline At the end of the treatment & $22.2 \pm 14.0$ \\
\hline Paired $t$-test & $t=3.248 ; d f=202 ; P<0.00 \mathrm{I}$ \\
\hline BDI-II: At the start of the treatment & $26.0 \pm 10.4$ \\
\hline At the end of the treatment & $21.1 \pm 12.8$ \\
\hline Paired $t$-test & $t=6.054 ; d f=20 \mathrm{I} ; P<0.00 \mathrm{I}$ \\
\hline ISMI: At the start of the treatment & $66.6 \pm 12.4$ \\
\hline At the end of the treatment & $63.1 \pm 13.8$ \\
\hline Paired $t$-test & $t=-2.310 ; d f=100 ; P<0.05$ \\
\hline DES & $15.4 \pm 13.7$ \\
\hline SDS - Work & $5.2 \pm 3.5$ \\
\hline SDS - Social Life & $6.1 \pm 2.6$ \\
\hline SDS - Family Life/Home Responsibilities & $5.8 \pm 2.7$ \\
\hline
\end{tabular}

Notes: Data are shown as mean \pm SD unless otherwise specified. $P<0.05$ was considered significant.

Abbreviations: AP, agoraphobia; SP, social phobia; PD, panic disorder; GAD, generalized anxiety disorder; MADD, mixed anxiety-depressive disorder; $C B T$, cognitive behavioral therapy; objCGl, objective Clinical Global Impression; subjCGI, subjective Clinical Global Impression; BDI-II, Beck Depression Inventory, the second edition; BAI, Beck Anxiety Inventory; DES, Dissociative Experience Scale; ISMI, The Internalized Stigma of Mental IIIness Scale; SDS, Sheehan Disability Scale.

and $13.9 \%$ of the patients had a disability pension. As for marital status, $42.1 \%$ of the patients were single, another $36.4 \%$ were married, and $18.7 \%$ divorced. More than half of the patients (58.4\%) had a partner (Table 1).

In all 209 patients, the primary diagnosis was anxiety disorder $(30.6 \%$ individuals had panic disorder, $6.2 \%$ agoraphobia, 20.6\% social phobia, $26.3 \%$ generalized anxiety disorder, and $11.7 \%$ mixed anxiety-depressive disorder).

Regarding the severity of the disorder, the average severity of the disorders ranged from "moderately ill" to "markedly ill" according to the objCGI and subjective CGI (subjCGI) severity. The mean severity of the anxiety and depressive symptoms (BAI and BDI-II, respectively) was also moderate. ${ }^{36,39}$

The total scores of the self-stigma, measured by ISMI at the start and the end of the treatment, reached average levels. ${ }^{43}$ The level of psychological dissociation, measured by DES, pointed to a slightly higher level of dissociation. ${ }^{44}$ The values of SDS indicated moderate disabilities in work, social life, and family life on average. ${ }^{47}$

\section{Changes during the therapy}

Significant improvements were observed in all parameters objCGI, subjCGI, BDI-II, and BAI (Table 1). The minimal improvement according to objCGI (a change of at least one point between the pre-post measurements) was shown by 182 patients (87.2\%), and a bigger improvement (the objCGI change of two points or more) was noticed in 124 individuals (59.3\%). A remission, defined as the last objCGI score of 1 or 2 , was achieved by 95 patients $(45.5 \%)$. The treatment response with regards to the depressive symptomatology, defined as an improvement of $30 \%$ of the initial BDI-II score, was shown by 79 patients (37.8\%). Similarly, the treatment response in the anxiety symptomatology, defined as an improvement of $30 \%$ of the BAI score, was found in 64 patients $(30.6 \%)$.

Additionally, 101 patients completed ISMI both at the start and at the end of the hospitalization (Table 1). Although the average level of the stigma significantly decreased during the treatment, the effect size was small (Cohen's $d=0.38$ ).

\section{Correlations of the demographic, clinical, and psychological characteristics and therapeutic change}

The relative change in objCGI positively correlated with the initial levels of depression (BDI-II), anxiety (BAI), dissociation (DES), and self-stigma (ISMI) (Table 2). This indicates the patients, who had less severe symptomatology (such as anxiety, depression, dissociation, and self-stigma) at the start of the treatment, improved more during the hospitalization.

The relative change of anxiety symptomatology (BAI) negatively correlated with BAI at the beginning of the treatment. On average, the more the patient was anxious at the start of the treatment, the more they improved during 
Table 2 Spearman's correlation coefficients between chosen predictive factors and indicators of the therapeutic change

\begin{tabular}{llll}
\hline Factors & Relative objCGI & Relative BAI & Relative BDI-II \\
\hline Age, years & $-0.03, \mathrm{~ns}$ & $-0.06, \mathrm{~ns}$ & $-0.09, \mathrm{~ns}$ \\
Onset of the disorder & $-0.13, \mathrm{~ns}$ & $0.00, \mathrm{~ns}$ & $-0.05, \mathrm{~ns}$ \\
Number of hospitalizations & $0.1 \mathrm{n}, \mathrm{ns}$ & $-0.04, \mathrm{~ns}$ & $0.03, \mathrm{~ns}$ \\
Length of the treatment & $0.10, \mathrm{~ns}$ & $-0.10, \mathrm{~ns}$ & $-0.8, \mathrm{~ns}$ \\
objCGI & $-0.06, \mathrm{~ns}$ & $0.02, \mathrm{~ns}$ & $0.1 \mathrm{l}, \mathrm{ns}$ \\
subjCGI & $0.11, \mathrm{~ns}$ & $-0.10, \mathrm{~ns}$ & $0.06, \mathrm{~ns}$ \\
BDI-II & $0.14^{*}$ & $0.02, \mathrm{~ns}$ & $-0.05, \mathrm{~ns}$ \\
BAI & $0.18^{*}$ & $-0.20^{* *}$ & $0.10, \mathrm{~ns}$ \\
DES & $0.17^{*}$ & $0.11, \mathrm{~ns}$ & $0.21 * *$ \\
ISMI - Total score & $0.28^{* * *}$ & $0.09, \mathrm{~ns}$ & $0.11, \mathrm{~ns}$ \\
SDS - Work & $-0.06, \mathrm{~ns}$ & $-0.03, \mathrm{~ns}$ & $-0.0 \mathrm{I}, \mathrm{ns}$ \\
SDS - Social Life & $0.14, P=0.05 \mathrm{I}$ & $0.02, \mathrm{~ns}$ \\
SDS - Family Life/Home Responsibilities & $0.03, \mathrm{~ns}$ & $0.03, \mathrm{~ns}$ & $0.01, \mathrm{~ns}$ \\
Antidepressant index & $0.04, \mathrm{~ns}$ & $0.02, \mathrm{~ns}$ & $-0.01, \mathrm{~ns}$ \\
Anxiolytic index & $-0.06, \mathrm{~ns}$ & $-0.05, \mathrm{~ns}$ & $0.02, \mathrm{~ns}$ \\
Antipsychotic index & $0.17, \mathrm{~ns}$ & $0.02, \mathrm{~ns}$ & $0.03, \mathrm{~ns}$ \\
\hline
\end{tabular}

Notes: $* P<0.05 ; * * P<0.01 ; * * * P<0.001$.

Abbreviations: objCGI, objective Clinical Global Impression; subjCGI, subjective Clinical Global Impression; BDI-II, Beck Depression Inventory, the second edition; BAI, Beck Anxiety Inventory; DES, Dissociative Experience Scale; ISMI, The Internalized Stigma of Mental Illness Scale; SDS, Sheehan Disability Scale; ns, non-significant.

its course. Lastly, the relative change in depressivity (BDI-II) was significantly positively connected with the initial level of dissociation (Table 2).

Men who attended the study improved in the severity of the depressive symptoms significantly more than women. The genders did not differ in the extent of change of the global symptomatology (objCGI) of anxiety (BAI) (Table 3).

Patients who were employed or self-employed showed a bigger improvement in global severity of the disorder than individuals without a job, but this difference was not observed in the changes in anxiety and depression levels. Also, patients with a partner improved significantly more than patients without a partner concerning the general severity of the disorder (Table 3).

\section{Mediation analysis}

Previous analyses indicated that the relative change of the objective (relobj) CGI might be significantly influenced by the initial level of self-stigma (ISMI), anxiety (BAI), depression (BDI-II), and dissociation (DES). Contrary to the expectations, the levels of disability (SDS) were not related to the main indicator of treatment change. Based on the theoretical background described in the Introduction, we proposed a mediation model explaining the ways through which self-stigma lowers treatment effectiveness.

The model consisted of self-stigma as a predictor; anxiety, depression, and dissociation as possible mediators, and the relative change of the psychopathology as an outcome criterion. The AMOS software was used for the calculations. The maximum likelihood method was used, as it is a gold standard in structural equation modeling and as it is robust against normality violations..$^{53}$

Figure 1 contains standardized estimates of the pathways. The three paths connecting ISMI with BAI, BDI-II, and DES were significant (in all cases $P<0.001$ ). However, none of the mediators were significantly related to the relobjCGI. Fit indices also revealed a bad model fit $\left(\chi^{2}=51.589\right.$; $d f=4$; significance: 0.001; Confirmatory Fit Index $(\mathrm{CFI})=0.675$; RMSEA $=0.244)$. As such, the anxiety, depression, and dissociation levels do not seem to explain the relationship between the self-stigma and the lower treatment effectiveness.

\section{Discussion}

The aim of this study was to confirm or disconfirm a main finding of the previous study, ${ }^{9}$ in which the self-stigma significantly influenced the treatment effect among patients with anxiety disorders, and to identify ways in which selfstigma does so.

The demographic structure of the sample was similar to other studies in gender, age, the age of onset, heredity, occupational status, and marital status. ${ }^{24,54,55}$ The rate of comorbidity was also similar to other studies. ${ }^{55}$

During the 6-week treatment consisting of psychotherapy (CBT or short psychodynamic therapy) and pharmacotherapy (in most patients), the participants significantly improved in the general severity of the disorder and the anxiety and depressive levels. Approximately half of the patients (45.5\%) reached a remission at the end of the treatment. Only $12.8 \%$ of the completers were non-responders. This is noticeably lower than a third of the completers - the average percent of 
Table 3 Relationship between selected demographic and clinical factors and therapeutic change

\begin{tabular}{|c|c|c|c|}
\hline Factors & Relative objCGI & Relative BAI & Relative BDI-II \\
\hline \multicolumn{4}{|l|}{ Gender } \\
\hline Male & $-0.37 \pm 0.28$ & $-0 .|4 \pm 0.5|$ & $-0.23 \pm 0.63$ \\
\hline Female & $-0.37 \pm 0.24$ & $-0.08 \pm 1.53$ & $-0.13 \pm 0.58$ \\
\hline Mann-Whitney U & $\mathrm{U}=4,549, \mathrm{~ns}$ & $\mathrm{U}=3,9 \mid 2, \mathrm{~ns}$ & $U=3,658 *$ \\
\hline \multicolumn{4}{|l|}{ Education } \\
\hline Primary & $-0.33 \pm 0.30$ & $-0.24 \pm 0.09$ & $-0.07 \pm 0.65$ \\
\hline Vocational training & $-0.38 \pm 0.29$ & $0.18 \pm 1.00$ & $-0.12 \pm 0.56$ \\
\hline Secondary & $-0.36 \pm 0.23$ & $-0.08 \pm 0.59$ & $-0.17 \pm 0.58$ \\
\hline Tertiary & $-0.40 \pm 0.22$ & $-0.53 \pm 2.70$ & $-0.28 \pm 0.67$ \\
\hline Kruskal-Wallis test & $\chi^{2}=1.508, \mathrm{~ns}$ & $\chi^{2}=4.219, \mathrm{~ns}$ & $\chi^{2}=1.187, \mathrm{~ns}$ \\
\hline \multicolumn{4}{|l|}{ Heredity } \\
\hline Yes & $-0.38 \pm 0.27$ & $-0.01 \pm 0.74$ & $-0.14 \pm 0.60$ \\
\hline No & $-0.36 \pm 0.24$ & $-0.21 \pm 1.73$ & $-0.19 \pm 0.59$ \\
\hline Mann-Whitney U & $\mathrm{U}=4,927, \mathrm{~ns}$ & $\mathrm{U}=4,798, \mathrm{~ns}$ & $U=5,02 \mathrm{I}, \mathrm{ns}$ \\
\hline \multicolumn{4}{|l|}{ Occupation } \\
\hline Yes & $-0.40 \pm 0.26$ & $-0.13 \pm 1.55$ & $-0.20 \pm 0.56$ \\
\hline No & $-0.33 \pm 0.24$ & $-0.04 \pm 0.59$ & $-0.1 I \pm 0.64$ \\
\hline Mann-Whitney U & $U=3,987^{*}$ & $U=4,720, \mathrm{~ns}$ & $\mathrm{U}=4,578, \mathrm{~ns}$ \\
\hline \multicolumn{4}{|l|}{ Pension } \\
\hline Yes & $-0.37 \pm 0.25$ & $-0.05 \pm 0.54$ & $-0.15 \pm 0.46$ \\
\hline No & $-0.37 \pm 0.26$ & $-0.10 \pm 1.36$ & $-0.17 \pm 0.61$ \\
\hline Mann-Whitney U & $U=2,5 \mathrm{I} 0, \mathrm{~ns}$ & $\mathrm{U}=2,407, \mathrm{~ns}$ & $\mathrm{U}=2,36 \mathrm{I}, \mathrm{ns}$ \\
\hline \multicolumn{4}{|l|}{ Marital status } \\
\hline Single & $-0.36 \pm 0.25$ & $-0.06 \pm 0.60$ & $-0.14 \pm 0.58$ \\
\hline Married & $-0.38 \pm 0.29$ & $-0.06 \pm 0.74$ & $-0.18 \pm 0.56$ \\
\hline Divorced & $-0.39 \pm 0.22$ & $-0.4 I \pm 2.5 I$ & $-0.17 \pm 0.73$ \\
\hline Widowed & $-0.34 \pm 0.21$ & $0.81 \pm 1.80$ & $-0.20 \pm 0.12$ \\
\hline Kruskal-Wallis test & $\chi^{2}=1.165, \mathrm{~ns}$ & $\chi^{2}=1.058, \mathrm{~ns}$ & $\chi^{2}=0.891, \mathrm{~ns}$ \\
\hline \multicolumn{4}{|l|}{ Partner } \\
\hline Yes & $-0.40 \pm 0.25$ & $-0.19 \pm 1.53$ & $-0.20 \pm 0.63$ \\
\hline No & $-0.33 \pm 0.26$ & $0.04 \pm 0.76$ & $-0.12 \pm 0.54$ \\
\hline Mann-Whitney U & $U=0.4250^{*}$ & $\mathrm{U}=4673, \mathrm{~ns}$ & $\mathrm{U}=4505, \mathrm{~ns}$ \\
\hline \multicolumn{4}{|l|}{ Psychotherapy } \\
\hline CBT & $-0.39 \pm 0.24$ & $-0.07 \pm 0.55$ & $-0.19 \pm 0.63$ \\
\hline Short psychodynamic therapy & $-0.36 \pm 0.27$ & $-0.1 I \pm I .63$ & $-0.14 \pm 0.57$ \\
\hline Mann-Whitney U & $\mathrm{U}=4,796, \mathrm{~ns}$ & $\mathrm{U}=4,86 \mathrm{I}, \mathrm{ns}$ & $U=4,556, \mathrm{~ns}$ \\
\hline \multicolumn{4}{|l|}{ Category of disorder } \\
\hline Panic disorder + agoraphobia & $-0.35 \pm 0.23$ & $0.16 \pm 1.10$ & $-0.05 \pm 0.70$ \\
\hline Social phobia & $-0.4 I \pm 0.20$ & $-0.06 \pm 0.48$ & $-0.20 \pm 0.55$ \\
\hline GAD + MADD & $-0.36 \pm 0.30$ & $-0.29 \pm 1.70$ & $-0.23 \pm 0.53$ \\
\hline Kruskal-Wallis test & $\chi^{2}=2.210, \mathrm{~ns}$ & $\chi^{2}=0.644$ & $\chi^{2}=2.121, \mathrm{~ns}$ \\
\hline \multicolumn{4}{|c|}{ Comorbidity with personality disorder } \\
\hline Yes & $-0.29 \pm 0.28$ & $-0.12 \pm 0.77$ & $-0.07 \pm 0.6 \mathrm{I}$ \\
\hline No & $-0.38 \pm 0.25$ & $-0.13 \pm 1.35$ & $-0.18 \pm 0.59$ \\
\hline Mann-Whitney U & $U=2,15 \mathrm{I}, \mathrm{ns}$ & $U=2,320, \mathrm{~ns}$ & $\mathrm{U}=2,302, \mathrm{~ns}$ \\
\hline \multicolumn{4}{|l|}{ Comorbidity with anxiety disorder } \\
\hline Yes & $-0.33 \pm 0.25$ & $-0.05 \pm 0.76$ & $-0.09 \pm 0.60$ \\
\hline No & $-0.38 \pm 0.26$ & $-0.1 I \pm I .4 I$ & $-0.19 \pm 0.59$ \\
\hline Mann-Whitney U & $U=3,327, n s$ & $U=3,747, \mathrm{~ns}$ & $U=3,438, n s$ \\
\hline
\end{tabular}

Notes: $* P<0.05$. Data are presented as mean \pm SD.

Abbreviations: objCGI, objective Clinical Global Impression; BAI, Beck Anxiety Inventory; BDI-II, Beck Depression Inventory, the second edition; GAD, generalized anxiety disorder; MADD, mixed anxiety-depressive disorder; $C B T$, cognitive behavioral therapy; ns, non-significant.

non-responders from a meta-analysis of studies using CBT or selective serotonin reuptake inhibitors. ${ }^{56}$ Interestingly, the patients improved the least in their anxiety levels. This may be attributed to anticipatory anxiety at the end of the treatment. The patients were about to head home to face issues that they had been working on resolving during the hospitalization. These worries and anxieties were often verbalized by the patients. Although most participants mastered 


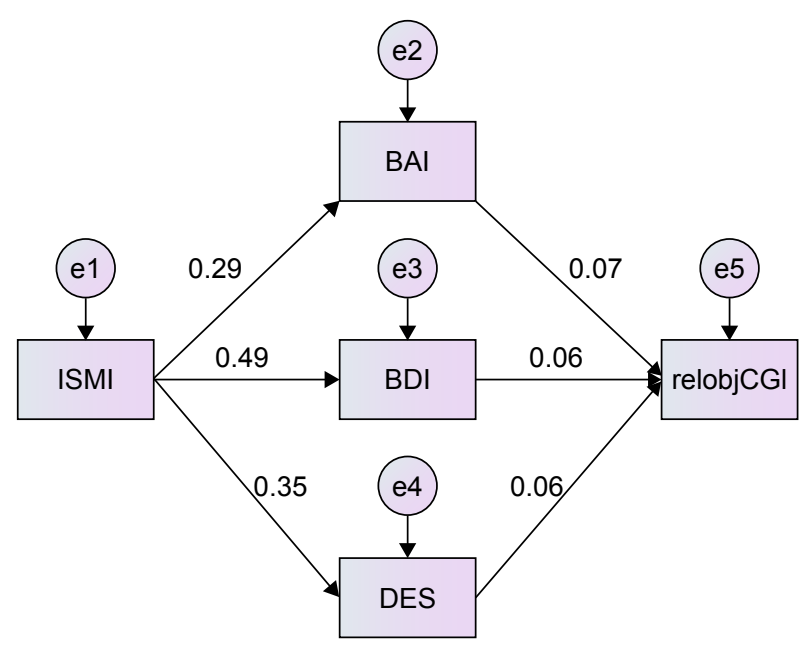

Figure I Mediation model with self-stigma as a predictor and the relative change of the overall psychopathology as an outcome.

Note: Numbers indicate the strength of pathways.

Abbreviations: BDI, Beck Depression Inventory; BAI, Beck Anxiety Inventory; DES, Dissociative Experience Scale; ISMI, The Internalized Stigma of Mental Illness Scale; relobjCGI, relative change of the objective Clinical Global Impression.

problem-solving, communication skills, and exposures, their return to their families and work often presented an exposure on its own. As such, the end of the treatment triggered anxiety in some patients. ${ }^{24}$

The mean level of the self-stigma slightly decreased during the treatment. However, the change was barely significant. This may indicate that the standardized psychotherapeutic treatment for anxiety disorders is not sufficient to tackle this topic. The patients from both therapeutic groups were acquiring cognitive skills to deal with anxiety and related issues, but self-stigma was not explicitly addressed. A more direct approach, such as Narrative Enhancement and Cognitive Therapy, ${ }^{57}$ could be more beneficial and perhaps could improve the treatment outcomes.

Based on the background described in the Introduction, we formulated several hypotheses. Three hypotheses explored the relationship between self-stigma and treatment effectiveness in anxiety disorders. The fourth hypothesis dealt with possible ways in which self-stigma worsens treatment outcomes.

In the first hypothesis, we expected that higher levels of self-stigma would lead to less improvement in anxiety symptoms, as self-stigma tends to increase anxiety., ${ }^{5,30}$ Our previous study also found that self-stigma predicted a lower change of anxiety symptoms in patients with anxiety disorders. ${ }^{9}$ In the present study, self-stigma failed to predict the change of anxiety during treatment. There are several explanations for this result. The correlation coefficient of this relationship in the study of Ociskova et $\mathrm{al}^{9}$ was small, $r=0.26$. The fact, that the coefficient was so small lowers the probability of the replication of the result. ${ }^{58}$ Another possibility is that the change in anxiety symptoms was too little to have sufficient power to discriminate potential predictors.

The second hypothesis stated that the initial level of self-stigma predicts a lower change of depressive symptoms. According to Link et al, ${ }^{31}$ self-stigma predicts the severity of depressive symptoms and could lead to symptoms of helplessness and hopelessness. This would suggest that self-stigmatizing patients would maintain symptoms of depression and would not change much during the treatment. We did not find that this was the case. On one side, self-stigma may predict depression severity (as seen here in the mediation analysis), which is in accordance with previous studies. ${ }^{6,8}$ However, self-stigma did not predict the change in depressive symptoms severity. Future research should explore this issue in a sample of depressed individuals, and focus on the specific symptoms of depression which are influenced by self-stigma.

The third hypothesis proposed that a higher initial level of self-stigma predicted a lower change of general severity of the mental disorder during treatment. In the study of Ociskova et al, ${ }^{9}$ the self-stigma significantly influenced the relative change of the objCGI, with a correlation coefficient $r=0.38$. The present study confirmed the finding. The self-stigma seems to hinder the therapeutic efforts during standardized treatment of anxiety disorders. Since self-stigma was not related to the relative change in anxiety and depressive symptoms, its impact on the therapeutic outcomes goes beyond its influence on the emotional symptoms. It may work through avoidant behavior or adherence issues. ${ }^{15,59}$ This hypothesis should be put under scrutiny in future studies.

The fourth hypothesis proposed several mediators between self-stigma and therapeutic change. We suggested that self-stigma may lower the treatment effectiveness through its maintenance of anxiety, depressive symptoms, dissociation, and disability. Even though the rationale behind this thought was based on theory and the findings of other authors, ${ }^{6,9,30,31}$ the results did not support the hypothesis. The correlation coefficients between the relative objCGI and the initial anxiety, depressive, and dissociation levels were negligible, and the mediation model did not prove their role in the process. Based on previous research, ${ }^{9,10}$ we found that the relative change of the objCGI was influenced by a number of quite small predictors (ranging from clinical, such as initial disorder severity, to psychological, like dissociation) which together mildly predicted the therapeutic outcome. This study 
concluded with same results as well. Stronger predictors have to be found to identify mediators of the relationship between self-stigma and treatment outcomes.

To sum up, self-stigma influences the outcome of the combined therapy of anxiety disorders. Future research should find the pathways in which self-stigma decreases the therapeutic effectiveness, to help with identifying effective ways of tackling both self-stigma and anxiety disorders.

\section{Limitations}

The investigation had several shortcomings. The data mainly came from self-evaluative methods. The use of such methods is conditioned on the capability of introspection of the patients and their readiness to be open in their reports. Another limitation is the broad spectrum of anxiety disorders which the patients had. A quarter of the participants had comorbidity with other anxiety disorders, and one in six suffered from a personality disorder. The patients were also treated with various medications and two different types of psychotherapy.

\section{Conclusion}

The outcomes of the treatment of anxiety disorders have repeatedly been shown to be suboptimal. It is important to address factors that diminish the therapeutic effects. Self-stigma is one of such factors. The mechanisms in which it does so have not been identified in this study. Future research should continue with the effort to find the pathways of self-stigma impact on therapy for improvement of the treatment outcomes.

\section{Disclosure}

The authors report no conflicts of interest in this work.

\section{References}

1. Corrigan PW, Rao D. On the self-stigma of mental illness: Stages, disclosure, and strategies for change. Can J Psychiatry. 2012;57(8): 464-469.

2. Seligman ME, Abramson LY, Semmel A, von Baeyer C. Depressive attributional style. J Abnorm Psychol. 1979;88(3):242-247.

3. Parcesepe AM, Cabassa LJ. Public stigma of mental illness in the United States: a systematic literature review. Admin Policy Ment Health. 2013;40(5):384-399.

4. Rüsch N, Corrigan PW, Powell K, et al. A stress-coping model of mental illness stigma: II. Emotional stress responses, coping behavior and outcome. Schizophr Res. 2009;110(1-3):65-71.

5. Drapalski AM, Lucksted A, Perrin PB, et al. A model of internalized stigma and its effects on people with mental illness. Psychiat Serv. 2013;64:264-269.

6. Corrigan PW, Larson JE, Rüsch N. Self-stigma and the "why try" effect: Impact on life goals and evidence-based practices. World Psychiatry. 2009;8(2):75-81.

7. Ociskova M, Prasko J, Kamaradova D, Grambal A, Sigmundova Z. Individual correlates of self-stigma in patients with anxiety disorders with and without comorbidities. Neuropsychiatr Dis Treat. 2015;11: 1767-1779.
8. Yanos PT, West ML, Gonzales L, Smith SM, Roe D, Lysaker PH. Change in internalized stigma and social functioning among persons diagnosed with severe mental illness. Psychiatry Res. 2012;200(2-3): 1032-1034.

9. Ociskova M, Prasko J, Latalova K, Kamaradova D, Grambal A. Psychological factors and treatment effectiveness in resistant anxiety disorders in highly comorbid inpatients. Neuropsychiatr Dis Treat. 2016;12: 1539-1551.

10. Prasko J, Grambal A, Kasalova P, et al. Impact of dissociation on treatment of depressive and anxiety spectrum disorders with and without personality disorders. Neuropsychiatr Dis Treat. 2016;12:2659-2676.

11. Prasko J, Ociskova M, Grambal A, et al. Personality features, dissociation, self-stigma, hope, and the complex treatment of depressive disorder. Neuropsychiatr Dis Treat. 2016;12:2539-2552.

12. Wood L, Byrne R, Morrison AP. An integrative cognitive model of internalized stigma in psychosis. Behav Cogn Psychother. 2017;45(6): 545-560.

13. Sirey JA, Bruce ML, Alexopoulos GS, et al. Perceived stigma as a predictor of treatment discontinuation in young and older outpatients with depression. Am J Psychiatry. 2001;158(3):479-481.

14. Cavelti M, Kvrgic S, Beck EM, Rüsch N, Vauth R. Self-stigma and its relationship with insight, demoralization, and clinical outcome among people with schizophrenia spectrum disorders. Compr Psychiatry. 2012;53(5):468-479.

15. Kamaradova D, Latalova K, Prasko J, et al. Connection between selfstigma, adherence to treatment, and discontinuation of medication. Patient Prefer Adherence. 2016;10:1289-1298.

16. Cinculova A, Kamaradova D, Ociskova M, et al. Adherence, selfstigma, and discontinuation of pharmacotherapy in anxiety disorders Cross-sectional study. Eur Psychiatry. 2015;30(Suppl.1):1113.

17. Fung KM, Tsang HW, Corrigan PW. Self-stigma of people with schizophrenia as predictor of their adherence to psychosocial treatment. Psychiatr Rehabil J. 2008;32(2):95-104.

18. Bandelow B, Michaelis S. Epidemiology of anxiety disorders in the 21st century. Dialogues Clin Neurosci. 2015;17(3):327-335.

19. Lépine JP. Epidemiology, burden, and disability in depression and anxiety. J Clin Psychiatry. 2001;62(Suppl 13):4-10.

20. Bystritsky A. Treatment-resistant anxiety disorders. Molec Psychiatry. 2006;11(9):805-814.

21. Baldwin D, Woods R, Lawson R, Taylor D. Efficacy of drug treatments for generalized anxiety disorder: systematic review and meta-analysis. BMJ. 2011;342:d1199.

22. Van Ameringen M, Mancini C, Pipe B, Greist JH, Hollander E, Montgomery SA, et al. Optimizing treatment in social phobia: A review of treatment resistance. CNS Spectr. 2004;9(10):753-762.

23. Holt RL, Lydiard RB. Management of treatment-resistant panic disorder. Psychiatry (Edgemont). 2007;4(10):48-59.

24. Prasko J, Kamaradova D, Cakirpaloglu S, et al. Predicting the therapeutic response to intensive psychotherapeutic programs in patients with neurotic spectrum disorders. Activitas Nervosa Super Rediviva. 2015; 57(1-2):30-39.

25. Hofman SG. Cognitive factors that maintain social anxiety disorder: A comprehensive model and its treatment implications. Cogn Behav Ther. 2007;36(4):193-209.

26. Wong QJJ, Rapee RM. The aetiology and maintenance of social anxiety disorder: A synthesis of complimentary theoretical models and formulation of a new integrated model. J Affect Disord. 2016;203:84-100.

27. Hettema JM, Neale MC, Kendler KS. A review and meta-analysis of the genetic epidemiology of anxiety disorders. Am J Psychiatry. 2001; 158(10):1568-1578.

28. Lysaker PH, Roe D, Yanos PT. Toward understanding the insight paradox: Internalized stigma moderates the association between insight and social functioning, hope, and self-esteem among people with schizophrenia spectrum disorders. Schizophr Bull. 2007;33(1):192-199.

29. Alonso J, Buron A, Bruffaerts R, et al. Association of perceived stigma and mood and anxiety disorders: results from the World Mental Health Surveys. Acta Psychiatr Scand. 2008;118(4):305-314. 
30. Lysaker PH, Yanos P, Outcalt J, Roe D. Association of stigma, selfesteem, and symptoms with concurrent and prospective assessment of social anxiety in schizophrenia. Clin Schizophr Relat Psychoses. 2010;4(1):41-48.

31. Link BG, Struening EL, Rahav M, Phelan JC, Nuttbrock L. On stigma and its consequences: Evidence from a longitudinal study of men with dual diagnoses of mental illness and substance abuse. J Health Soc Behav. 1997;38:177-190.

32. International Classification of Disorders. Mental and behavioural disorders: Research diagnostic criteria. 10th revision (Czech translation). Prague: Prague Psychiatric Centre; 1996.

33. Sheehan DV, Lecrubier Y, Sheehan KH, et al. The Mini-International Neuropsychiatric Interview (M.I.N.I.): The development and validation of a structured diagnostic psychiatric interview for DSM-IV and ICD-10. J Clin Psychiatry. 1998;59(Suppl 20):22-33.

34. Guy W. ECDEU Assessment manual for psychopharmacology. Rockville: DHEW; 1976.

35. Kadouri A, Corruble E, Falissard B. The improved Clinical Global Impression Scale (iCGI): Development and validation in depression. BMC Psychiatry. 2007;7:7.

36. Beck AT, Epstein N, Brown G, Steer RA. An inventory for measuring clinical anxiety: Psychometric properties. J Consult Clin Psychology. 1988;56:893-897.

37. De Ayala RJ, Vonderharr-Carlson DJ, Kim D. Assessing the reliability of the Beck Anxiety Inventory scores. Educ Psychol Meas. 2005;65(5): $742-756$.

38. Kamaradova D, Prasko J, Latalova K, et al. Psychometric properties of the Czech version of the Beck Anxiety Inventory - Comparison between diagnostic groups. Neuro Endocrinol Lett. 2015;36(7): $706-712$.

39. Beck AT, Steer RA, Ball R, Ranieri W. Comparison of Beck Depression Inventories-IA and II in psychiatric outpatients. J Pers Assess. 1996; 67:588-597.

40. Storch EA, Roberti JW, Roth DA. Factor structure, concurrent validity, and internal consistency of the Beck Depression Inventory - Second Edition in a sample of college students. Depress Anxiety. 2004;19(3): 187-189.

41. Ociskova M, Prasko J, Kupka M, et al. Psychometric evaluation of the Czech Beck Depression Inventory-II in a sample of depressed patients and healthy controls. Neuro Endocrinol Lett. 2017;38(2):98-106.

42. Ritsher JB, Otilingam PG, Grajales M. Internalized stigma of mental illness: Psychometric properties of a new measure. Psychiatry Res. 2003;121(1):31-49.

43. Ociskova M, Prasko J, Kamarádová D', et al. Self-stigma in psychiatric patients - Standardization of the ISMI scale. Neuro Endocrinol Lett. 2014;35(7):624-632.
44. Bernstein EM, Putnam FW. Development, reliability, and validity of a dissociation scale. J Nerv Ment Dis. 1986;174(12):727-735.

45. Waller DA, Gullion CM, Petty F, Hardy BW, Murdock MV, Rush AJ. Tridimensional Personality Questionnaire and serotonin in bulimia nervosa. Psychiatry Res. 1993;48(1):9-15.

46. Ptacek R, Bob P, Paclt I. Skala disociativnich zkusenosti - ceska verze [Dissociative Experiences Scale - A Czech version]. Ceskoslovenska psycholologie. 2006;50(3):262-272. Czech with an English abstract.

47. Sheehan DV, Harnett-Sheehan K, Raj BA. The measurement of disability. Int Clin Psychopharmacol. 1996;11(Suppl 3):89-95.

48. Leon AC, Shear MK, Portera L, Klerman GL. Assessing impairment in patients with panic disorder: the Sheehan Disability Scale. Soc Psychiatry Psychiatr Epidemiol. 1992;27(2):78-82.

49. Sheehan KH, Sheehan DV. Assessing treatment effects in clinical trials with the discan metric of the Sheehan Disability Scale. Int Clin Psychopharmacol. 2008;23(2):70-83.

50. Arbuckle R, Frye MA, Brecher M, et al. The psychometric validation of the Sheehan Disability Scale (SDS) in patients with bipolar disorder. Psychiatry Res. 2009;165(1-2):163-174.

51. Cohen J. Statistical power analysis for the behavioral sciences (second edition). Hillsdale: Lawrence Erlbaum Associates; 1988.

52. EMEA. Guideline for good clinical practice. London: EMEA. Available from: http://www.ema.europa.eu/docs/en_GB/document_library/ Scientific_guideline/2009/09/WC500002874.pdf. Accessed September 15, 2017.

53. Finney SJ, DiStefano C. Non-normal and categorical data in structural equation modeling. In: Hancock GR, Mueller RD, editors. Structural Equation Modeling: A Second Course. Greenwich: Information Age Publishing; 2006:269-314.

54. Alonso J, Angermeyer MC, Bernert S, et al. Prevalence of mental disorders in Europe: results from the European Study of the Epidemiology of Mental Disorders (ESEMeD) project. Acta Psychiatr Scand Suppl. 2004;(420):21-27.

55. Michael T, Zetsche U, Margraf J. Epidemiology of anxiety disorders. Epidemiol Psychopharmacol. 2007;6(4):136-142.

56. Taylor S, Abramowitz JS, McKay D. Non-adherence and non-response in the treatment of anxiety disorders. J Anxiety Disord. 2012;26(5): 583-589.

57. Roe D, Hasson-Ohayon I, Mashiach-Eizenberg M, Derhy O, Lysaker PH, Yanos PT. Narrative Enhancement and Cognitive Therapy (NECT) effectiveness: A quasi-experimental study. J Clin Psychol. 2014;70(4): 303-312.

58. Open Science Collaboration. Estimating the reproducibility of psychological science. Science. 2015;349(6251):aac4716.

59. Corrigan PW, Watson AC. Understanding the impact of stigma on people with mental illness. World Psychiatry. 2002;1(1):16-20.
Neuropsychiatric Disease and Treatment

\section{Publish your work in this journal}

Neuropsychiatric Disease and Treatment is an international, peerreviewed journal of clinical therapeutics and pharmacology focusing on concise rapid reporting of clinical or pre-clinical studies on a range of neuropsychiatric and neurological disorders. This journal is indexed on PubMed Central, the 'PsycINFO' database and CAS,

\section{Dovepress}

and is the official journal of The International Neuropsychiatric Association (INA). The manuscript management system is completely online and includes a very quick and fair peer-review system, which is all easy to use. Visit http://www.dovepress.com/testimonials.php to read real quotes from published authors. 